\title{
Predation on early life stages is decisive for year-class strength in the Barents Sea capelin (Mallotus villosus) stock
}

\author{
Harald Gjøsæter ${ }^{1 *}$, Elvar H. Hallfredsson ${ }^{2}$, Nina Mikkelsen ${ }^{3}$, Bjarte Bogstad $^{4}$, and Torstein Pedersen ${ }^{3}$ \\ ${ }^{1}$ Institute of Marine Research and Hjort Centre for Marine Ecosystem Dynamics, Bergen, Norway \\ ${ }^{2}$ Institute of Marine Research, Tromsø, Norway \\ ${ }^{3}$ UIT The Arctic University of Norway, Tromsø, Norway \\ ${ }^{4}$ Institute of Marine Research, Bergen, Norway
}

*Corresponding author: e-mail: harald.gjoesaeter@imr.no; harald@imr.no

Gjøsæter, H., Hallfredsson, E. H., Mikkelsen, N., Bogstad, B., and Pedersen, T. Predation on early life stages is decisive for year-class strength in the Barents Sea capelin (Mallotus villosus) stock. - ICES Journal of Marine Science, doi: 10.1093/icesjms/fsv177.

Received 1 December 2014; revised 16 September 2015; accepted 18 September 2015.

Year-class strength of Barents Sea capelin has been monitored closely since the early 1970 s and during this $\sim 45$ years period three short periods of almost total recruitment failure leading to three stock collapses have been observed. These events triggered much attention since there was a large commercial fishery for capelin, but also because of observed ecosystem effects attributed to the first of these collapse events. This attention motivated research to clarify mechanisms behind the recruitment failures, and many papers have been published regarding the causes of these events. Here, we review this literature and try to put the various investigations into context. Most of the research conducted gives evidence in favour of a hypothesis that was formulated after the first recruitment failure event in the mid-1980s that predation on capelin larvae was the main cause of recruitment failure. Most studies also support the hypothesis that young herring (Clupea harengus) was the main predator on capelin larvae, but other predators like young-of-the-year cod (Gadus morhua) and haddock (Melanogrammus aeglefinus) probably also played a role. Investigations of the effect of predators such as haddock, red king crab (Paralithodes camtschaticus), diving birds, and capelin on the demersal capelin eggs have also been reviewed. Usually, these predators are found to consume capelin eggs, but most likely not to an extent that would affect the recruitment to a noticeable degree. It is concluded that the predation on capelin larvae is the main reason for the observed recruitment failures, although predation from the predators reviewed here can hardly be the only reason for almost total recruitment failures observed in some periods.

Keywords: Barents Sea, capelin, mortality, predation, recruitment.

\section{Introduction}

Before Johan Hjort's (1914) book "Fluctuations in the great fisheries of Northern Europe", the view was widely held that fluctuation in catches of important species was due to migrations and hence fish availability to the fishers. Hjort's discovery of huge variation in strength of recruiting year classes was basic and gave rise to a new field of study. However, his idea that mass starvation due to lack of suitable food was instrumental to the survival rate from egg to age of recruitment to the fishery has been challenged. An alternative hypothesis stating that predation on young stages might be more important has been put forward and discussed by several authors (see the comprehensive review by Bailey and Houde, 1989).
The Barents Sea capelin (Mallotus villosus) stock represents a well-studied fish stock where data are available for investigating recruitment mechanisms. This stock has fluctuated significantly due to recruitment variation during the last 30 years, and a specific hypothesis, the "Hamre hypothesis", explaining this recruitment variation as an effect of predation on capelin larvae by young herring (Clupea harengus) was suggested. Also, the invasive species red king crab (Paralithodes camtschaticus) spread from Russian waters to the main capelin spawning areas during this period, and many held the view that the crabs would have a detrimental effect by feeding on capelin eggs. Other predators on capelin eggs and larvae, like young-of the year cod (Gadus morhua) and haddock

(c) International Council for the Exploration of the Sea 2015.

This is an Open Access article distributed under the terms of the Creative Commons Attribution License (http://creativecommons.org/ licenses/by/4.0/), which permits unrestricted reuse, distribution, and reproduction in any medium, provided the original work is properly cited. 
(Melanogrammus aeglefinus), as well as adult haddock, were additional candidate stressors to cause capelin recruitment failures.

Capelin is a small short-lived pelagic osmerid fish inhabiting northern latitude areas, where they are central to the functioning of ecosystems (Carscadden and Vilhjálmsson, 2002). They serve as forage fish for many predators encompassing fish, benthic invertebrates, sea mammals, and seabirds. The Barents Sea stock is the world's largest population of capelin and plays a pivotal role in the Barents Sea (Gjøsæter, 1998). This semelparous stock spends its whole life cycle in the Barents Sea, spawning demersally on coarse substrates along the northern coasts of Norway and Russia and feeding in the central and northern Barents Sea (Figure 1). The stock has been closely monitored since the early 1970s (Gjøsæter et al., 1998b; Toresen et al., 1998) and has undergone

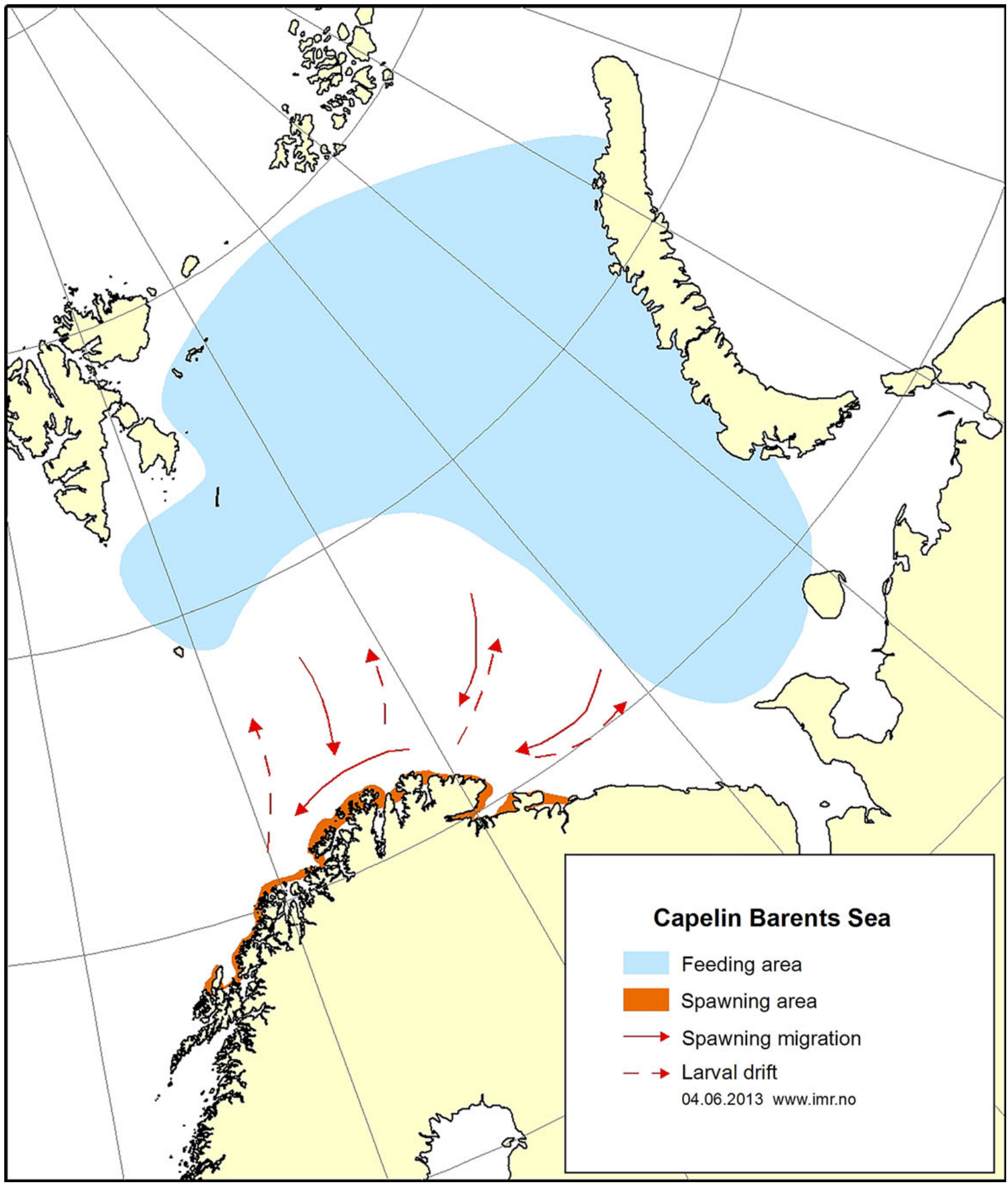

Figure 1. Distribution and migration of the Barents Sea capelin stock. 


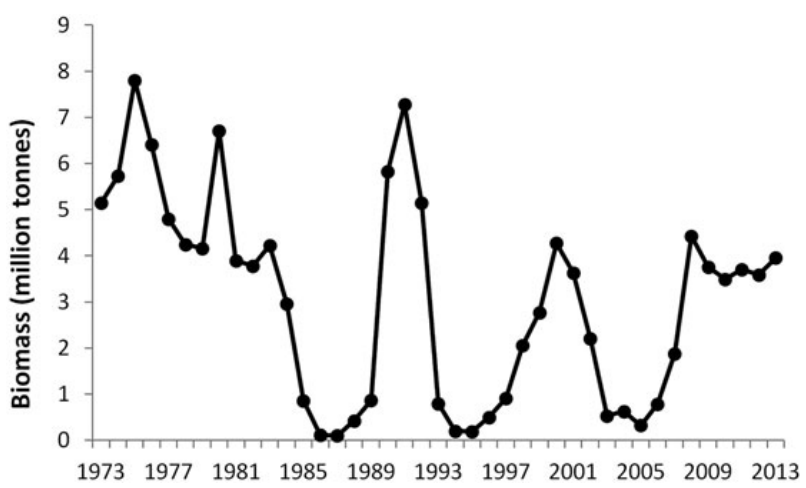

Figure 2. Stock size of capelin (1 year old and older) as estimated during acoustic surveys during September.

three "stock collapses"; in the mid-1980s, the mid-1990s, and the mid-2000s (Gjøsæter et al., 2009; Figure 2). These events gave rise to major research activity because of an important capelin fishery by the Norwegian and the Russian pelagic fishing fleets, but also because in particular the first stock collapse caused a great ecosystem disturbance. During that event birds died from hunger, and seals invaded coastal areas drowning by the thousands in fishers' nets. Cod, the most important commercial species in the Barents Sea, suffered from shortage of food and the growth rates were halved (Gjøsæter et al., 2009).

Unlike the situation for many other fish stocks, a relatively high correlation between spawning-stock biomass and recruitment (abundance of 1 year olds) has been found for this capelin stock, but episodically this relationship seems to break down (Gjøsæter and Bogstad 1998; Mikkelsen and Pedersen, 2004). The age distribution in the capelin stock before, during, and after the three stock collapses revealed that recruitment failure was the main reason for the sudden decline in stock size, although there was an increase in natural mortality of juveniles and adults during the collapses. The spawning mortality of Barents Sea capelin is regarded to be nearly total (Christiansen et al., 2008) and few live to be older than five years. Consequently, 2 or 3 years of recruitment failure in a row will have drastic effects on the stock size. To understand the recruitment mechanisms is, therefore, of prime importance for understanding the stock dynamics.

In the Barents Sea, the very small numbers of 1-year-old capelin during the main autumn survey in 1985 and again in 1986 (1984 and 1985 year class) caused Hamre $(1991,1994)$ to argue that the collapse of the capelin stock evident from 1986 onwards was mainly due to recruitment failure. The larval production, as estimated from the larval survey in 1984 and 1985 was at a high level, in fact the estimate in 1985 was the highest in the time series until then. The spawning stock was of ample size and clearly plenty of larvae were produced that should have allowed for rich year classes to emerge these years. Hamre (1991) pointed to this fact and concluded that a mass mortality must have taken place among the larvae during summer and autumn (partly before and partly after the 0-group survey in August). He argued that this mortality "is assumed to have been caused by abundant year classes of juvenile herring." Gjøsæter (1995) analysed the data both from the capelin stock and the fishery during this period. He confirmed Hamre's findings that the almost total mortality on the early life stages of capelin during these years, rather than recruitment overfishing, was the major cause of the stock collapse.
To link the observed stock collapses to recruitment failures caused by high mortality in the early life stage rather than other reasons, for instance, overfishing was a major step towards a better understanding of the underlying mechanisms. However, the increased mortality in the early life stages could not be ascribed to any particular reason. The predation-by-herring hypothesis posed by Hamre was one of several possibilities. Alternatives could be decimation by other predators during the egg or larval stage, or increased mortality from starvation.

Investigations on the spawning grounds of the Barents Sea capelin in the 1970s suggested that haddock was the most important fish predator on capelin eggs, while the examined saithe (Pollachius virens) and cod did not feed on eggs (Sætre and Gjøsæter, 1975). In the same study, capelin was observed to cannibalize their eggs and fertilized eggs were found in their stomach (Sætre and Gjøsæter, 1975). Diving ducks (king eiders Somateria spectabilis, common eider Somateria mollissima, and long-tailed ducks Clangula hyemalis) were also found to feed on eggs at depths shallower than $50 \mathrm{~m}$.

A fair amount of research has been conducted to elucidate recruitment mechanisms of Barents Sea capelin during the last 2030 years. Here, we review the results of this research and try to sum up what can be concluded so far. We also extend some analyses to include new data that have become available, and point to further work that should be conducted to increase the understanding of what mechanisms govern the survival of capelin at the egg and larval stage.

\section{Results}

\section{Stock abundance estimates and stock dynamics}

The surveillance of the Barents Sea capelin has been organized by the Institute of Marine Research, IMR, Bergen, and the Polar Institute of Fisheries and Oceanography, PINRO, Murmansk yearly. The effort has been substantial, especially during the first $2-3$ decades after the start in 1972. Annual surveys were carried out in January (immatures and matures, spawning migration), March-April (spawning), June (larvae), August (0-group), and September (acoustics, 1 year olds and older). At present, only the 0 -group survey and the acoustic survey covering the whole stock still go on, but they are now integrated parts of an "Ecosystem survey" that is carried out jointly by IMR and PINRO in August-September every year (Michalsen et al., 2013). Three time series have been particularly useful when studying recruitment; the larval surveys in June (Alvheim, 1985) giving estimates of larval abundance 1-2 months post-hatching, the 0-group surveys in August (Eriksen et al., 2009) giving estimates of $\sim 3$ - to 4-month-old larvae, and the total stock survey in September (Gjøsæter et al., 1998a) giving estimates of year-class strength at age 1 and older. These three annual surveys have allowed for analysis of which year classes were particularly weak or strong, as well as at which stage the year-class strength was determined (Gjøsæter, 1995, 1998; Gundersen and Gjøsæter, 1998; Hjermann et al., 2010). The larval surveys were started in 1981 and were discontinued in 2006, while 0-group estimates and acoustic estimates of age 1 and older capelin are available also after 2006.

Determining the spawning-stock biomass (SSB) of capelin is not straightforward. Virtual population analysis (VPA) approaches are not reliable for a stock with almost total spawning mortality, and natural mortality considerably higher than the fishing mortality. Attempts to measure (by acoustic methods) the amount of capelin approaching the coast to spawn in early spring have also failed. Therefore, the stock assessment is based on the assumption 
that the acoustic estimate in autumn each year is an absolute estimate of age 1 and older capelin. The SSB at spawning time (1 April) is then modelled from the autumn survey assuming all capelin $>14 \mathrm{~cm}$ would mature, and reducing the number of maturing fish by catches and assumed natural mortality due to predation by cod. The management is based on a target escapement strategy, setting the quota so that there is a $95 \%$ probability for the SSB to be $>200000$ tonnes.

A revised series of $S S B$ estimates back to 1990 is given by Gjøsæter et al. (2015), based on retrospective runs with the capelin assessment model that is currently used within ICES (Gjøsæter et al. 2002). Here, we have updated this series using the 2014 cod VPA (ICES, 2014a), and extended it back to 1987. Calculating SSB further back in time using this approach is not possible, because for the years 1984-1986, the model calculated vanishing SSB, although the maturing stock in autumn was large according to acoustic estimates. This suggests that the acoustic estimate is underestimating the total stock size. In the period 1984-1986, the fishing pressure on capelin was much higher than in later years, and the model used is much more likely to give vanishing $S S B$ due to fishing than due to predation as fishing is subtracted directly while predation by cod is applied as a mortality rate.

The year-class strength as estimated during the three life stages larva (June), 0-group (August), and 1 year olds (September next year) is shown as a Paulik diagram in Figure 3. The basic data are shown in Supplementary data, Table S1. The three periods when the stock dwindled to very low levels (1985-1989, 1993-1997, and 2003-2006) are all within the time frame covered by this diagram. The larval index was highest in 1999, and was high in the period 1998-2002. Both the 0-group index and the 1-group index were high at the beginning and at the end of the time series. The 1989 year class is the strongest observed at age 1 and was strong at the 0-group stage, although at the 0-group stage, both the 2008 and 2012 year classes were stronger than the 1989 year class. The

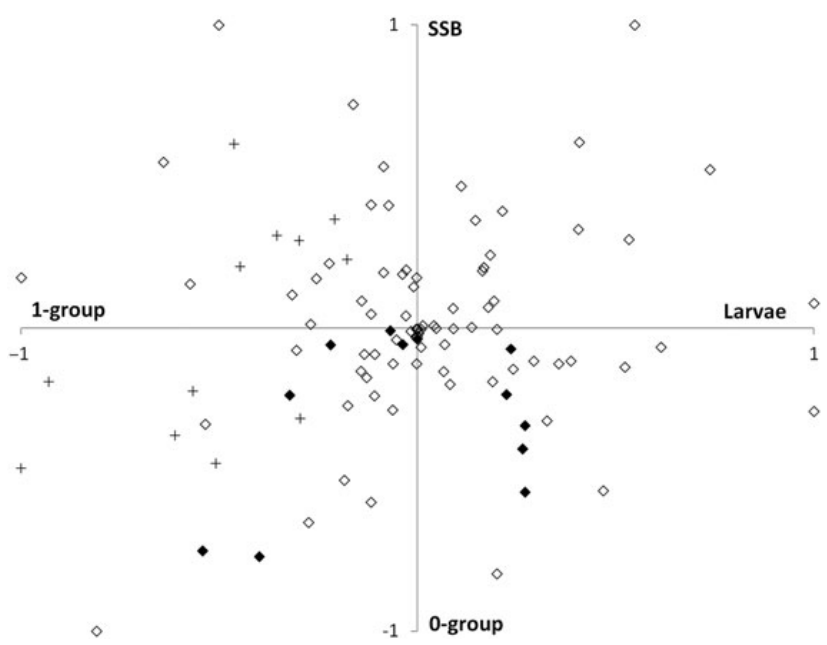

Figure 3. Paulik diagram for Barents Sea capelin: SSB estimates for the cohorts 1987-2012, larvae estimates for the cohorts 1981-2006 and 0 -group, and 1-group estimates for the cohorts 1981-2012. The SSB estimates are based on updated runs with the capelin assessment model (see text for explanation). The indices of abundance at the larval, 0 -group, and 1-group stage are taken from ICES (2014a). Filled diamonds: cohorts 1981-1986, open diamonds: cohorts 1987-2006, crosses: cohorts $2007-2012$. larval index and the 0-group index show no significant correlation ( $n=26, R=0.24, p=0.24$ ), whereas the 0 -group index and the 1-group index are highly correlated $(n=26, R=0.78, p<<$ $0.01)$. The lack of significant correlation between the larval and 0 -group indices is due to several cohorts with medium or high larval abundance but low 0-group abundance.

If we take the 1-group index to define year-class strength (Gundersen and Gjøsæter, 1998), this analysis suggests that the yearclass strength is fairly well established during the 0-group survey in August, when the larvae are $\sim 4$ months old. It also shows that the year-class strength is poorly defined 2 months earlier, in June, when the larval survey is conducted. Therefore, processes that take place during the first summer to a large degree determine the yearclass strength. The larval index is not available for years outside the period 1981-2006. The 0-group index and the 1-group index are available also for the year classes 2007-2012, and the correlation for the total period is also highly significant $(n=32, R=0.58$, $p<<0.01$ ). Therefore, the conclusion drawn above seems to hold also for the longer period.

\section{Predation on capelin eggs}

Survival of demersal eggs of marine fish stocks such as the Barents Sea capelin and Atlantic herring is generally high when predation mortality is omitted (Dragesund and Nakken, 1973; Gjøsæter et al., 1974; Skaret et al., 2002). Conversely, egg predation by haddock caused alternate stable population levels in Georges Bank Atlantic herring (Richardson et al., 2011). Neither Atlantic herring nor capelin provides parental care for their demersal eggs, which makes them exposed to predation. Predation on capelin eggs from haddock, capelin, and red king crab has been under study in the period from 2002 to 2006 (Slotte et al., 2006; Mikkelsen, 2013).

Egg cannibalism can contribute to the total natural mortality in wild populations and thereby be an important regulatory mechanism. High density of either cannibal or prey through increased encounter rate between the two promotes cannibalism (Smith and Reay, 1991). In both the Barents Sea capelin (Sætre and Gjøsæter, 1975) and in beach spawning capelin at Newfoundland (Templeman, 1948), egg cannibalism has been observed. In 2002, such cannibalism by adult capelin was studied at the spawning areas at the coast of Finnmark (Slotte et al., 2006). That the spawning distribution was restricted to a narrow area at the easternmost spawning grounds in 2002, suggesting a high density of spawners there implies that egg cannibalism may occur as a density-dependent mechanism in the Barents Sea capelin. The occurrence of cannibalism increased with stage of maturity and was highest in spent fish. The amount of cannibalism was higher in males than in females, 63.6 and $46.4 \%$, respectively, which is lower than recordings in beach spawning capelin at Newfoundland where $94 \%$ of males and $86 \%$ of females had been feeding on capelin eggs (Templeman, 1948). When Slotte et al. (2006) estimated the minimum egg consumption attributed to egg cannibalism, no digestion was assumed. This assumption was based on laboratory studies where a degeneration of the alimentary system was observed in spent males (J. S. Christiansen, pers. comm.). On average, spent females and males consumed $\sim 75$ and 85 eggs, respectively, which corresponded to a minimum mortality of $1-2 \%$ of the total egg production. The low estimated mortality indicates that egg cannibalism did not act as an important regulatory mechanism in 2002, despite the narrow spawning distribution, which could have enhanced cannibalistic behaviour. 
Mikkelsen (2013) investigated predation on the demersal capelin egg by haddock and red king crab. Haddock is a native species in the Barents Sea ecosystem and its stock size has been fluctuating considerably in the period from 1973 up to present (ICES, 2014a). Although it is well known that capelin and capelin eggs are important prey for haddock during spring season (Dolgov, 2002; Bogetveit et al., 2008), few attempts have been made to study the extent of this predation. The red king crab is an invasive species in the Barents Sea ecosystems and it was important to study the magnitude of capelin egg predation by the crab, as its distribution overlaps the capelin spawning grounds at the coast of Finnmark in spring when eggs are available. The introduced red king crab became abundant in Varangerfjord during the 1990s. This fjord is the easternmost fjord in northern Norway and is close to the release site of crabs in Murmansk fjord in Russia. Since 2000, standardized bottom-trawl surveys have provided annual indices of abundance and distribution of the red king crab in Norwegian waters (Hvingel et al., 2012). The stock abundance peaked in 2008, while thereafter the stock has been declining (Windsland et al., 2014). Yet, the crab continues to expand its distribution area due to its great migratory ability (Windsland et al., 2014).

The occurrence of capelin eggs in red king crab and haddock was investigated by stomach analysis from samples taken at identified spawning grounds for capelin in 2005 and 2006. For red king crab, the consumption of eggs was estimated during the period when eggs were available, taking into account the uncertainty in data by using Monte Carlo simulations. In addition, both capelin egg density and the abundance of crab at spawning sites were estimated to investigate if the crabs showed an aggregative response to capelin egg density.

Capelin eggs occurred more frequently in haddock (2005: 34\%, 2006: 64\%) than in red king crab (2005: 10\%, 2006: 23\%) and the red king crab did not show aggregative behaviour to capelin egg density in the field. When comparing the occurrence of capelin eggs and adult capelin as prey in haddock, Mikkelsen (2013) found that the occurrence of eggs increased significantly from 2005 to 2006, while the occurrence of adult capelin decreased, indicating that haddock may have switched from feeding on capelin in 2005 to eggs in 2006. The change in diet composition could be an effect of capelin as alternative prey may already have been eaten up at the time of sampling in 2006, by haddock and other capelin predators (Mikkelsen, 2013).

The estimated consumption of capelin eggs by the red king crab accounted for 0.04 and $2.23 \%$ of capelin eggs available, respectively, in the years of study by Mikkelsen (2013), which is similar to that estimated by Anisimova et al. (2005) at the coast of the Kola Peninsula in 2001. When compared with a capelin egg mortality caused by amphipod predation in coastal regions of Newfoundland, these estimates are low. DeBlois and Leggett (1993) estimated that egg consumption by Calliopius laeviusculus could account for from 5 to $30 \%$ of the total egg deposition, but these eggs were deposited in the intertidal areas. Nevertheless, the total capelin egg consumption by the red king crab may be underestimated because consumption by juvenile crabs was not included in the study. Also, red king crabs were observed to damage and spill a substantial amount of fish eggs during feeding activities, which will lead to a higher mortality of eggs than estimated from stomach data. However, based on the consumption estimates, Mikkelsen (2013) concluded that egg consumption by the red king crab may influence mortality of eggs, but is not hampering recruitment.

\section{Predation on capelin larvae}

\section{Herring as predator}

The hypothesis that juvenile herring grazed down the capelin larvae was not readily accepted but initiated various studies to test this hypothesis. Herring is normally not found in large amounts in the Barents Sea, but occasionally, herring larvae from the spawning areas along the western Norwegian coast enter the Barents Sea, and stay there for 2-3 years before they leave the area to join the adult stock in the Norwegian Sea. The amount of young herring in the Barents Sea will, therefore, vary to a large extent. During the 1970 s, the area was practically void of herring, and the 1983 year class was the first major year class to enter this area since the strong 1959 year class. The herring of the 1983 year class left the Barents Sea in spring 1986 and the capelin stock regained its pre-collapse size when the strong 1989 year class recruited to the stock. From 1986 to 1991 small amounts of herring entered the Barents Sea. In 1992 and in 1993, new strong year classes of herring entered this area, allowing fieldwork to be carried out to look for hard evidence that herring were preying on capelin larvae. Huse (1994) sampled one- to three-year-old herring from trawl stations where herring and larval capelin overlapped. He analysed 799 herring stomachs from 18 stations in 1992, and, 2560 herring stomachs from 48 stations in 1993. The stomach content analysis revealed that there was a large variation in the amount of capelin larvae found in herring stomachs. Few larvae were found in most stomachs, but in one $17 \mathrm{~cm}$ herring 40 capelin larvae were found, and constituted more than half of the stomach content. In 1993, the length of the capelin larvae ingested ranged from 12 to $25 \mathrm{~mm}$. The mean length of capelin larvae sampled from the sea was lower $(13.1 \mathrm{~mm})$ than those from the herring stomachs $(17.6 \mathrm{~mm})$. Huse (1994) concluded that herring preyed selectively on the larger capelin larvae, but noted that this result may also have been caused by an avoidance reaction of larger larvae towards the Gulf III used to sample capelin larvae.

When the strong 1991 and 1992 year classes of herring had left the Barents Sea there was again small amounts of herring found there until after the turn of the century. A large part of the effort in the project "Capelin and Herring in the Barents Sea - coexistence or exclusion?" (BASECOEX-Norwegian Research Council project no $140290)$ was devoted to investigate the herring-capelin interaction, with the ambition to examine this process quantitatively. For this work, surveys were conducted in the Barents Sea in 2001-2004, when once more abundant year classes of young herring entered this area.

Field surveys designed to estimate mortality rates due to predation from herring on capelin larvae were carried out in JulyAugust 2001 and June-July 2003 (Hallfredsson and Pedersen, 2009). Juvenile herring were widely distributed in 2001 and overlapped with capelin larvae over a wide area, whereas in 2003 the herring were more aggregated. The study focused on predation in the areas of predator-prey overlap. Herring concentration was estimated by acoustics supplemented with trawl samples, herring stomachs were examined, and capelin larvae and zooplankton concentration estimated from sampling by Gulf III high-speed plankton sampler. At all stations with herring where the concentration of capelin larvae was $>10 \mathrm{~m}^{-2}$, capelin larvae were found in $>7 \%$ of the herring stomachs. The concentration of capelin larvae and occurrence of capelin larvae in the herring stomachs was significantly correlated for stations with 10 or more herring in the trawl 
catches. Statistical models revealed that concentration of capelin larvae and copepods and the occurrence of euphausiids in the stomachs significantly affected the number of capelin larvae per predator stomach. The westwards movement of herring along the coast of Finnmark may be a response to heavy zooplankton predation and hence decreasing zooplankton abundance in areas with dense herring concentrations. As the herring feeding migrations are governed by abundant krill and copepods drifting with currents from the southwest, the capelin larvae will be preyed upon in the belt-like area with high herring densities. The dynamic behaviour of this system was reflected to some extent in the data.

Since rapid digestion of fish larvae is a major constraint in field investigations of predation mortality, it was hypothesized that the anterior part of the predator stomach would contain less digested fish larvae, and would provide more valuable information about the recent feeding history than more posterior sections. Godiksen et al. (2006) analysed stomach contents from schools with lesser sandeel (Ammodytes tobianus) and herring caught in an area with relatively high abundance of capelin larvae. They sectioned the stomach contents into five sections and analysed each section separately. Most capelin larvae were found in the anterior sections of the stomachs close to the oesophagus, indicating that rapid digestion rates of larvae compared with other stomach content reduced the abundance in the posterior sections. Herring have two feeding modes; particle-feeding at relatively low prey densities and filter feeding at higher prey densities. Switching between particulate and filter feeding in herring occurs at $\sim 13000$ Calanus sp. copepodites $\mathrm{m}^{-3}$ (Gibson and Ezzi, 1992), which is ca. 20-100 times the concentration observed in the Godiksen et al. (2006) study. Thus, it is unlikely that filter feeding had occurred. Still, the anterior sections of the stomachs had clear alternating layers of either copepods or capelin larvae and krill. This shows that the individual herring switched between feeding on either copepods or on krill and capelin larvae. This prey switching is likely to be caused by alternate feeding in patches with above-average abundance of either copepods or patches of krill and capelin larvae. Furthermore, this suggested that abundance of copepods as alternative prey to capelin larvae could affect predation rates on capelin larvae and that copepod abundance could be a key factor in scaling mortality rates of capelin larvae in the Barents Sea. Later studies using statistical models on a much more extensive material confirmed that high abundance of copepods reduced predation rate from herring (Hallfredsson and Pedersen, 2009). The abundance of C. finmarchicus copepodites is reduced in the upper part of the water column from late June onwards (Falkenhaug et al., 1997; Tande et al., 2000), and this may increase mortality rate of capelin larvae when planktivorous fish change their diet from copepods to capelin larvae and krill during summer. A simplified model with only capelin larvae concentration as predictor (Model 3 in Hallfredsson and Pedersen, 2009) was converted to a functional response relationship using an experimentally derived digestion rate estimate for capelin larvae in herring stomachs (Figure 4). This functional response was later used in spatio-temporal models (Pedersen et al., 2009a, b; Wiedmann et al., 2012).

\section{Mortality rate by herring predation}

Huse (1994) estimated the impact predation had on larval capelin mortality by a simple multiplicative model based on the method for estimation of predation outlined by Bailey and Houde (1989). The total number of capelin larvae ingested by herring $(T P)$ was

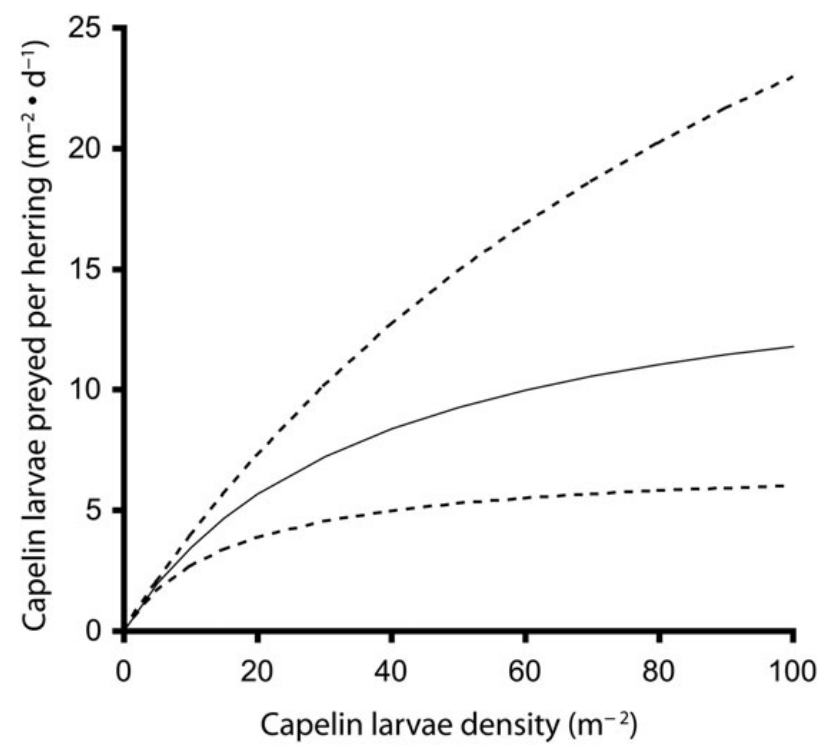

Figure 4. Functional response for herring predation on capelin larvae as estimated by Model 3 (continuous line), using a digestion rate of $0.3 \mathrm{~h}^{-1}$ (Hallfredsson et al. 2007). Broken lines are the $95 \%$ confidence intervals. From Hallfredsson and Pedersen (2009).

estimated from the model

$$
T P=X \times C \times N \times D \times M,
$$

where $X$ is average number of capelin larvae in herring stomachs, $C$ is proportion of herring containing capelin larvae, $N$ is estimated number of 1 - to 3-year-old herring in the Barents Sea, $D$ is number of days that capelin larvae are confined to the predatory field of herring, and $M$ is number of meals per day. The values of most of the parameters in this model were realized to be highly uncertain, and rather than presenting an estimate of larval mortality, various scenarios representing a range of values of $M$ were presented. One such scenario, based on three meals per day and $60 \mathrm{~d}$ of predation, and an estimate of total abundance of capelin larvae each year (Huse and Toresen, 1995), resulted in mortalities on capelin larvae of 22 and 38\% in 1992 and 1993. The author was fully aware that this model was too simplistic to give realistic estimates of the total predation mortality, but still might indicate that the amount of herring found in the Barents Sea these years would have the potential to graze down a large proportion of the capelin larvae present.

Huse and Toresen (1995) applied the same model as used by Huse (1994) to extend the estimates of herring predation on capelin larvae back to 1983, the first year that a high amount of young herring entered the Barents Sea since the early 1960s. Again, various scenarios were presented, indicating that $4-10 \%$ of the capelin larvae could have died because of herring predation during 1984-1986, while during the years 1991-1993 from 25 to $67 \%$ of the capelin larvae could have been removed by herring predation.

In a later paper, Huse and Toresen (2000) revisited the material from the field studies in 1992-1993, and concluded that the observed feeding rates of capelin larvae by herring were in accordance with estimated encounter rates between individual herring and capelin larvae. Due to the uncertainties about the input to a predation model, they did not calculate any estimates of larval mortality, but concluded that the observed rates were probably too low to 
explain the almost total larval mortality observed these years. They hypothesize that predation from herring could still be of major importance due to increased swimming speed and selective feeding in areas where herring encounter particularly high densities of capelin larvae, so-called feeding frenzies, a mechanism previously demonstrated for sandeel (Ammodytes marinus) feeding on herring larvae (Christensen, 1983).

To estimate the number of fish larvae consumed by predatory fish in the field from predator stomach data, knowledge about the digestion rates of prey is important. Hallfredsson et al. (2007) made an experimental study to establish digestion rates for capelin larvae in herring stomachs. Captured herring was fed with frozen capelin larvae along with copepods to simulate natural stomach contents, and ambient temperature was similar to temperature in field when predation occurs. Digestion rate to disappearance $(D)$ was calculated assuming an exponential relationship; $N_{\mathrm{t}}=a(\exp \cdot(-D \times$ $t)$ ), where $N_{\mathrm{t}}$ is the average number of recognizable larvae at time $t$ and $a$ is the average number of larvae consumed by the herring. Their conclusion was that digestion rate to disappearance $(D)$ for capelin larvae in herring stomachs of $0.30 \mathrm{~h}^{-1}$ would be the most suitable to apply to Atlantic herring stomach data from that area. Capelin larvae were digested much faster than the crustaceans that made up most of the stomach content (Figure 5).

Based on field surveys in the period from late June to early August, Hallfredsson and Pedersen (2009) estimated the average number of capelin larvae eaten per juvenile herring per day $\left(N_{\mathrm{e}}\right)$ by the formula (2) (Bajkov, 1935; Munk, 2002):

$$
N_{\mathrm{e}}=M S C \times D \times 24,
$$

where MSC is the mean number of capelin larvae found in the herring stomachs, and $D$ is the digestion rate to disappearance, equal to $0.30 \mathrm{~h}^{-1}$ (see above). The average sea temperatures from surface to a depth of $50 \mathrm{~m}$ were $8.3^{\circ} \mathrm{C}$ in 2001 and $6.6^{\circ} \mathrm{C}$ in 2003 . This was close to the temperature of $7.6^{\circ} \mathrm{C}$ in the digestion rate experiments of Hallfredsson et al. (2007), and thus the use of $D$ was found to be appropriate for the field data sampled during all day at day lengths longer than $20 \mathrm{~h}$. The temperature interval 6.6$8.3^{\circ} \mathrm{C}$ represents a span in digestion rate of $\sim 20 \%$ (Durbin et al., 1983). Capelin larvae were observed in the herring stomachs at 11 of 24 stations and at 8 of 16 stations where herring were caught

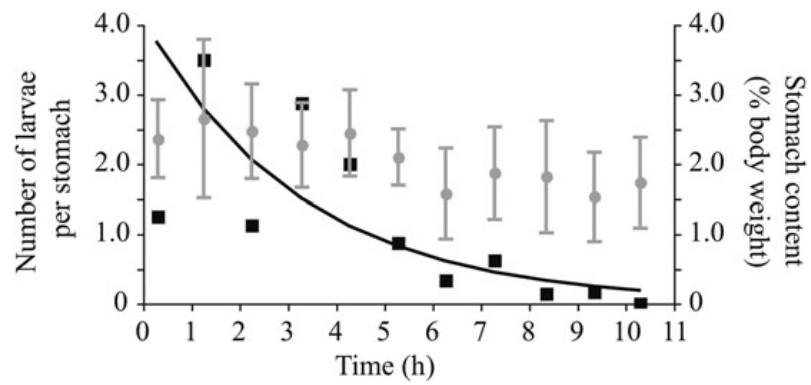

Figure 5. Average numbers of capelin larvae in juvenile Atlantic herring stomachs (filled squares) by time after ingestion from a digestion rate experiment. An exponential function was fitted to the numbers of larvae assuming a Poisson error distribution (-). The curve was fitted by $y=4.09 \mathrm{e}^{-0.305 x}$. Also shown are mean total stomach content as percentage of herring body mass with $95 \% \mathrm{Cl}$. From Hallfredsson et al. (2007). (C) 2007 The Authors. Journal compilation (C) 2007 The Fisheries Society of the British Isles. in 2001 and 2003, respectively. At those stations, an estimated 7.3 and $9.9 \%$ of the capelin larvae were eaten by herring per day in 2001 and 2003, respectively. This indicates that predation by juvenile herring may have a considerable impact on capelin larvae survival in years with high herring abundance and extended overlap in distribution.

\section{Other predators on capelin larvae}

Being a part of the community of small planktonic organisms during the summer, capelin larvae are probably prey to several fish species, and capelin larvae have been identified in stomachs of sandeel, cod, saithe, and haddock (Table 1). Capelin larvae was observed in $20 \%$ of 110 stomachs from lesser sandeel in one targeted trawl haul from the outer part of the Tana Fjord in Northern Norway at a survey in July 2003, on average 1.8 larvae per stomach with larvae (Godiksen et al., 2006).

Predation from pelagic 0 -group cod may affect mortality rates of Barents Sea capelin larvae and this was examined based on surveys carried out in 2002 and 2003 (Hallfredsson and Pedersen, 2007). Juvenile cod abundance was estimated by acoustics combined with trawl samples that also provided stomach samples, and GULF III was used to get abundance estimates of capelin larvae and other plankton. Capelin larvae were observed in 17 and $8 \%$ of the cod stomachs in 2002 and 2003, respectively, with 1-15 larvae per stomach (Figure 6). Cod predation was observed at 19 of 50 stations in 2002 and 19 of 37 stations in 2003. The stomach contents and zooplankton samples were dominated by copepods and krill. The number of capelin larvae in cod stomachs increased with increasing capelin larvae abundance and cod length, but decreased with increasing stomach content of copepods and prey abundance of krill.

Small cod juveniles with lengths of $\sim 20-50 \mathrm{~mm}$ were able to consume relatively large capelin larvae with the upper value for capelin larvae — cod juvenile length ratio of $\sim 1$ (Hallfredsson and Pedersen, 2007). The results from this study suggested that maximum prey size increases with predator size, whereas minimum prey size is more independent of predator size, a pattern often observed in piscivorous fish (Scharf et al., 2000).

The number of capelin larvae eaten per juvenile cod was modelled by Hallfredsson and Pedersen (2007). The time in minutes for $50 \%$ probabilities $(A)$ that capelin larvae could be recognized after ingestion in cod stomachs was estimated experimentally, and depended on the lengths of predator and prey. This allowed the number of capelin larvae eaten per juvenile cod per day $\left(N_{\mathrm{e}}\right)$ to be estimated using the following formula (Olson and Boggs, 1986):

$$
N_{\mathrm{e}}=\left(\frac{M S C}{A}\right) \times 60 \times 24
$$

where MSC is the mean number of capelin larvae found in the cod stomachs from samples taken during the whole day. The variable $N_{\mathrm{e}}$ was estimated for each station, as well as combined for each coverage and year. The total number of capelin larvae eaten by cod at each station per day per square meter was calculated as the product of $N_{\mathrm{e}}$ and cod abundance. The estimated overall predation mortality rate from juvenile cod on capelin larvae was $\sim 1.5 \%$ per day for both years (2002 and 2003) and can potentially have a significant effect on the survival of capelin larvae, depending on spatial and temporal overlap in the different years. In August-September, there is often a large overlap in horizontal distribution of the capelin larvae and 0-group cod (Sundby et al., 1989; Gjøsæter, 1998), and 
Table 1. Some potential predators on capelin larvae in the Barents Sea with references to studies where predation has been recorded.

\begin{tabular}{|c|c|c|c|c|}
\hline Predator & Predator size $(\mathrm{cm})$ & Predation on eggs & Predation on larvae & Reference \\
\hline \multirow[t]{3}{*}{ Herring } & $13-25$ & & + & Huse and Toresen $(1995,2000)$ \\
\hline & $10-29$ & & + & Hallfredsson and Pedersen (2009) \\
\hline & $10-15$ & & + & Godiksen et al. (2006) \\
\hline \multirow[t]{2}{*}{ Capelin } & $9.5-16$ & + & + & Huse and Toresen (1996) \\
\hline & $15-19$ & + & & Slotte et al. (2006) \\
\hline Cod adult & & - & & Sætre and Gjøsæter (1975) \\
\hline \multirow[t]{3}{*}{ Cod juveniles } & & & + & Dalpadado and Bogstad (2004) \\
\hline & $4-5$ & & + & Helle (1993) \\
\hline & $1-5$ & & + & Hallfredsson and Pedersen (2007) \\
\hline \multirow[t]{4}{*}{ Haddock } & & + & & Sætre and Gjøsæter (1975) \\
\hline & $30-45$ & + & & Bogetveit et al. (2008) \\
\hline & & + & & Mikkelsen (2013) \\
\hline & $14-65$ & & + & Hallfredsson (2006) \\
\hline \multirow[t]{2}{*}{ Saithe } & $36-74$ & & + & Hallfredsson (2006) \\
\hline & & - & & Sætre and Gjøsæter (1975) \\
\hline Lesser sandeel & $12-18$ & & + & Godiksen et al. (2006) \\
\hline Lumpfish (Cyclopterus lumpus) & & & - & Hallfredsson (2006) \\
\hline Three-spined stickleback (Gasterosteus aculeatus) & $3.4-4.2$ & & - & Hallfredsson (2006) \\
\hline Red king crab & & + & & Mikkelsen (2013) \\
\hline Diving ducks & & + & & Sætre and Gjøsæter (1975) \\
\hline
\end{tabular}

+ means a positive finding, - means a negative finding. Updated from Hallfredsson (2006).

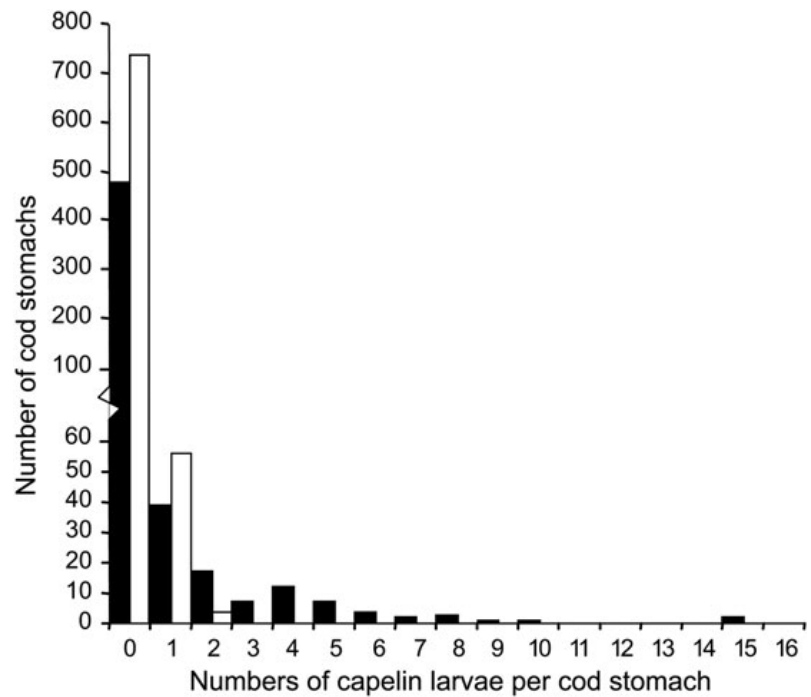

Figure 6. Frequency distribution of number of capelin (Mallotus villosus) larvae found in the stomachs of 0 -group cod (Gadus morhua) in 2002 (solid bars) and 2003 (open bars). Note that the $y$-axis is cut at $y=70$. From Hallfredsson and Pedersen (2007). C) Canadian Science Publishing or its licensors.

if a mortality rate of $\sim 1.5 \% \mathrm{~d}^{-1}$ by cod predation lasts for several months, this may result in a significant decrease in the abundance of capelin larvae. In contrast to herring, the small pelagic 0 -group cod will drift with the capelin larvae, resulting in a prolonged period of prey-predator overlap.

A model of the predation-prey interaction between juvenile cod and capelin larvae with a novel proto-moments approach (Pope, 2003) was developed and fitted to survey estimates in spring and autumn 2002 and 2003 (Hallfredsson and Pope, 2007). The model approach produced a realistic development through time for length distributions, concentration in numbers and the biomass of young-of-the-year capelin and cod, but population dynamics also clearly depends on assumptions about growth and other parameters. The rate of predation mortality for the whole period was estimated to 0.03 and $0.11 \mathrm{~d}^{-1}$ for 2002 and 2003, respectively. These should be considered as maximum values, because the model operates on densities per square meter and does not take into account changes in spatial overlap as the species develop and disperse over wider areas during late summer. Thus, this is a rather simple approach that has not been applied to herring predation were more complex modelling has been pursued.

\section{Spatio-temporal models}

Hallfredsson and Pedersen (2009) recognized that the kind of study they conducted can only give snapshots of the predation intensity of herring on capelin larvae at the time and place of the surveys. The predation from herring on capelin larvae in the Barents Sea occurs when capelin larvae are advected offshore in a north- and east-wards direction and herring migrate westwards against the prevailing currents. Thus, it was suggested to integrate the temporal and spatial effects of prey and predator movement to obtain the best estimates of the total effect of herring predation on capelin recruitment. Whether or not predation represents a significant constraint on capelin recruitment depends on the frequency and duration of predation incidences, as well as the presence of alternative prey. They suggested that their functional response models might be suitable as submodels in larger models that address those aspects. This was done in various subsequent model studies (Pedersen et al., 2009a, b; Wiedmann et al., 2012).

Applying hydrodynamic and particle-tracking models, field surveys, and experimental data, Pedersen et al. (2009b) investigated the spatial and temporal mortality rate of capelin larvae in 2001 as a function of herring predation. Capelin larvae were reduced to $20-$ $50 \%$ in 2 weeks in accordance with different simulation scenarios. The hypothesis that herring predation is a main cause of poor capelin recruitment in years when herring are very abundant in the Barents Sea (Hamre 1994) was supported by the results of this modelling work. 
Based on the various studies reviewed above, it seems reasonable to conclude that predation mortality high enough to affect the year-class strength to any noticeable degree is much more likely to take place at the larval stage than at the egg stage. At least for the potential predators on capelin larvae studied so far, the herring is clearly the most probable candidate for being able to have profound effects on a capelin year class, first, because herring seemingly have the capacity to graze down large proportions of capelin larvae in the areas where there is overlap between these two, and second, because herring is probably the only pelagic feeder with large enough fluctuations in abundance to be able to explain the year-to-year difference in predation.

\section{Stock-recruit modelling}

Gjøsæter and Bogstad (1998) analysed stock-recruit data for capelin and modified the Beverton and Holt $(\mathrm{B}-\mathrm{H})$ relationship by including terms for juvenile herring biomass affecting the halfvalue but not the maximum recruitment (Equation 4)

$$
R=\frac{\alpha \times S S B}{\beta+\gamma \times \text { Herring }+\delta \times S S B} .
$$

This modified $\mathrm{B}-\mathrm{H}$ function fitted the data better than the original B-H based on data from 1972 to 1996 . A further study using data from 1973 to 2000 attempted to test a modified Ricker spawning stock-recruitment in addition to $\mathrm{B}-\mathrm{H}$, and also tested if inclusion of terms for winter temperature and 0-group cod would increase the fit (Mikkelsen and Pedersen, 2004). However, the modified B-H model with a herring term still showed the best fit to the data. The modified $\mathrm{B}-\mathrm{H}$ model showed that the strongly asymptotic capelin recruitment in the absence of juvenile herring changes to an almost linear relation between $S S B$ and recruitment when herring biomass was high ( $>1.6$ million tons).

We updated the analysis of effects of herring biomass on capelin recruitment by including data from the period after the two papers cited above were published. The most recent VPA estimates of ages 1 and 2 herring at 1 January in a given year (ICES, 2014b) was used as a measure of the young herring biomass in the Barents Sea in year $y$, applying constant weights at age of $10 \mathrm{~g}$ for age 1 herring and $44 \mathrm{~g}$ for age 2 herring as used in stock projections in ICES (2014b). These weights are higher than those previously used in calculations of herring influence on capelin recruitment, 9 and $20 \mathrm{~g}$, respectively (e.g., Gjøsæter and Bogstad, 1998), but the new values are thought to better reflect the stock situation (ICES, 2014b). There is uncertainty whether the amount of 3-year-old herring should be included, because in some years these will still be in the Barents Sea in spring, while in other years they will have left this area earlier. On the other hand, some 1- to 2-year-old herring will normally stay outside the Barents Sea (in Norwegian Fjords and in the Norwegian Sea). Here, we have chosen to exclude the 3 years old.

In the plot of recruitment of capelin at age 1 and spawning-stock biomass for the cohorts 1987-2012 (Figure 7), the points were divided into three categories according to herring biomass in the year when the cohort was spawned: $<450000$ tonnes (low), 450 000-1300000 tonnes (medium), and >1300000 tonnes (high). All nine points in the high herring biomass category have a considerably higher biomass than found in the other herring biomass categories, while the division between the low (nine points) and medium (eight points) categories is somewhat arbitrary and was set so that the number of points in each of the categories was approximately equal.

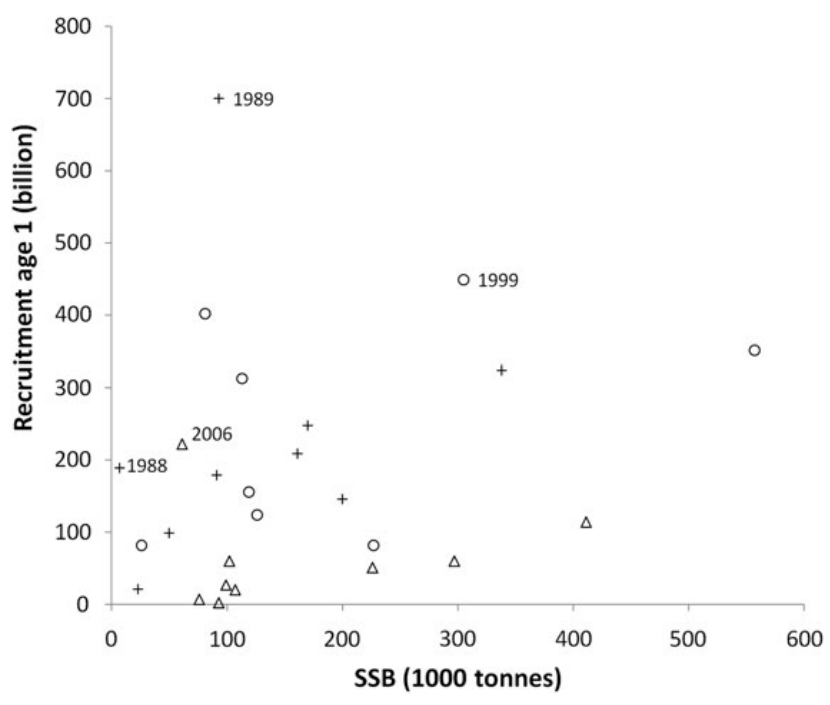

Figure 7. SSB/R plot for Capelin, based on data from ICES (2014a) (Table 9.6). Cohorts 1987-2012. Points coded according to herring biomass age $1+2$ in spawning year. Circles-herring biomass $<450000$ tonnes, crosses-herring biomass between 450000 tonnes and 1.3 million tonnes, triangles-herring biomass $>1.3$ million tonnes.

All points in the high herring biomass category give poor recruitment except one (the 2006 year class), while the difference between low and medium points is minor (Figure 7). It should also be noted that the 1988 year class produced average recruitment despite a very small capelin spawning stock. Including points from the years before 1987 would give two additional points in the high herring biomass category $(1984,1985)$ and one additional point in the low category (1986), all with low recruitment and low SSB (in particular low SSB in 1986). For the years 1983 and earlier, all points would be in the low herring biomass category as the young herring abundance in that period was very low. From these results, a reasonable conclusion is that capelin recruitment will normally fail when there is more than $\sim 1.3$ million tonnes of young herring in the Barents Sea.

There are, however, considerable uncertainties both with the estimation of capelin spawning stock (vanishing SSB in several years before 1987 using the present model approach) and young herring abundance. A review providing a realistic time series of young herring abundance in the Barents Sea is needed. The available data sources (VPA back-calculation as described above) and survey estimates both have considerable uncertainties and biases. For the backcalculations, there is uncertainty in the $M$ value used $(M=0.9$ year $^{-1}$ is used at present for herring at age $0-2$ ) as well as in the choice of age groups to be included. The survey estimates for young herring are rather noisy and several cohorts are difficult to track (ICES, 2014b). In view of these uncertainties, it was decided not to update model fit in equation (4) in the present paper.

\section{Discussion Biological mechanisms}

Recruitment failure due to high mortality on prerecruits seems to have started the process towards Barents Sea capelin stock collapse in the 1980s, 1990s, and 2000s. However, it is likely that cod feeding on a diminishing adult capelin stock amplified the effect of recruitment failures, as constant predation pressure measured as a biomass removal will cause an increasing mortality rate. Also, 
after a couple of years with recruitment failure the spawning stock may be reduced to a level where recruitment is hampered, although survival conditions for larvae are decent (e.g. the years 1986-1988). In any case, it is reasonable to conclude that recruitment failure was the underlying cause of the three stock collapses observed and described here.

It should be emphasized that when discussing the mechanisms for recruitment failures, we focus more on the variation in mortality on prerecruits than on the total mortality from the egg stage to 1 year olds, which is close to $100 \%$ even in years with recruitment success.

Based on the literature reviewed here, the predation mortality on the egg stage is not considered a major driving force in recruitment failure in the Barents Sea capelin. Egg cannibalism accounted for 1$2 \%$ of the total egg production in 2002 while egg predation by the red king crab accounted for $<2.5 \%$ of the eggs available at the study site. Although haddock fed more frequently on capelin eggs than the red king crab in both 2005 and 2006, this egg consumption is most likely not high enough to extensively hamper capelin recruitment. Concurrent with the capelin stock recovery after the "stock collapse" in the mid-2000s, the red king crab stock peaked in 2008 and the stock of northeast Arctic haddock was increasing to a historically high level in the period from 2010 to present (ICES, 2015). If the egg loss due to predation from haddock and red king crab was decisive for capelin recruitment, the capelin stock could probably not have recovered during this period. Contrary to these findings, Richardson et al. (2011) found that egg predation by haddock may drive substantial changes in herring population levels.

Most of the research we have reviewed and the new analysis we have made based on observed abundance at various early life stages of capelin suggest that year-class strength is mainly determined at the larval stage. However, they do not provide exclusive evidence that predation alone, and in particular from a single predator, can explain the almost total mortality observed on capelin larvae in some periods. This is particularly true for the research conducted in 1991-1992, when the recruitment failures that initiated the second stock collapse were observed. Although herring stand out as the most potent predator also during that period, the estimated amount of capelin larvae found in herring stomachs was generally too low to explain the high death rates among capelin larvae, and additional hypotheses involving "feeding frenzies" was needed to suggest that predation from herring was the main cause for the mass mortality of capelin larvae. However, based on the fieldwork conducted in the early 2000s (Hallfredsson, 2006; Hallfredsson and Pedersen, 2007, 2009, Hallfredsson and Pope, 2007) it seems very likely that predation is the main course of mass mortality among the capelin larvae.

There is clear evidence from the repeated measurements of capelin larval abundance in June and August during their first year of life and in September the year after, that year-class strength is not determined in June, when the larvae are $\sim 2$ months old. It is to a large degree determined 2 months later, although it is clear (Supplementary Table S1) that in some years with a particular high mortality rate from June to August, there is also a high mortality rate during the following year. The capelin larvae normally metamorphose during spring in their second year of life. These observations are only compatible with the hypothesis that mortality variation during larval life is essential to the degree of recruitment success. That does not mean that the total mortality at earlier (or later) stages is unimportant, only that this is the time when the most substantial variation in mortality takes place. There are some caveats associated with these repeated measurements. The larval and the 0-group surveys have been conducted with the same sampling gears (a Gulf III high-speed plankton sampler at the larval survey and a Harstad trawl at the 0-group survey) and according to the same protocols during the period 1981 to 2006. In some years, however, the coverage during the larval survey was incomplete. The trawl used to sample 0-group is not particularly well suited for sampling small sizes of capelin, especially in rough weather. The capelin larvae are often found hanging in the trawl meshes and could be washed out of the trawl before the trawl is taken on board. Such factors may have introduced variation to both these time series, but probably not bias. The acoustic instrumentation used to estimate the abundance of 1-group capelin have undergone some changes in this period, and are likely more sensitive to weak echoes during the last part of the series (Gjøsæter et al., 1998b). It is normally stated in the reports from these surveys that the 1-group estimates should be regarded to be less accurate than those of older capelin, because of the behaviour of the young stages. The changes in the sensitivity of echosounders could induce bias, while behaviour like near-surface distribution would most likely only introduce random variation.

If larval mortality is essential to determining recruitment success in capelin, the options predation and death of other reasons, like starvation, should be weighed against each other. Two pieces of evidence are relevant in this context. Experiments with capelin larvae in predator-free enclosures have shown that capelin larvae had very high survival rates when exposed to normal food concentrations (Ivarjord et al., 2008). In one of the experiments, from 48 to $61 \%$ of the larvae in various experimental groups were still alive after $>2.5$ months. The other piece of evidence is the various investigations reviewed here, where several potential predators have been shown to consume capelin larvae to an extent that would remove substantial portions of the larvae present where predator and prey overlapped for a longer period.

The idea that capelin larvae are consumed by other fish is certainly not new. Both at Newfoundland (Templeman, 1948) and at Iceland (Magnusson, 1968) it was observed that many abundant fish species, including herring, fed heavily on capelin larvae. In a mesocosm experiment in Flødevigen, Norway (Øiestad and Moksness, 1979), herring larvae preying on capelin larvae were assumed to take place but not actually observed. The authors released $\sim 25000$ herring larvae in a $4400 \mathrm{~m}^{2}$ basin. When the herring larvae were 35 days old $\sim 3000$ capelin yolk sac larvae were released in the basin, and additional 50000 capelin yolk sac larvae were released in the basin 2 weeks later. Both groups of capelin larvae met very good feeding conditions and showed rapid growth. They did, however, disappear more or less completely during the weeks after, and the authors argue that most likely they were brought to extinction due to predation from the herring larvae.

If one accepts predation as a main mechanism determining the year-class strength of capelin, the question remains whether young herring or other predators are the key predator. The results of the field experiments in the early 2000s suggest that 1 - to 2 -year-old herring are the most potent predators. Age zero herring normally enter this area too late in the season and may be too small to have any impact on capelin larvae born the same year. Not only is the herring the most potent predator, it is also probably the only potential predator to vary enough in abundance to explain the large variation in mortality from year to year. Other predators do not show the large interannual variability in biomass and extensive horizontal overlap with capelin larvae that are characteristic for juvenile herring in the Barents Sea. In his synthesis, Hallfredsson 
(2006) suggested that the combined predation on capelin larvae by other predators than herring may be extensive but relatively stable from year to year compared with herring. Herring drift into the Barents Sea as early juveniles and remains there for 2-4 years before emigrating to join the adult stock in the Norwegian Sea (Huse and Toresen, 2000). As only the juvenile of herring is present in the Barents Sea and year-class strength of herring varies substantially, the herring shows much larger temporal fluctuations in abundance than other potential predators. Thus, herring predation is more likely to cause variation in annual capelin larvae survival then the other predators.

To point at young herring as the main cause of capelin recruitment failures does not exclude that other predators may also play important roles, at least in some years. In 2002, capelin recruitment was for instance low despite much capelin larvae. That year, herring abundance was low but predation from juvenile cod was high (Hallfredsson and Pedersen, 2007). Neither does it imply that recruitment failure will strike the capelin stock every time young herring enter the Barents Sea. For example in 1999 (marked on Figure 7), the 1999 cohort of capelin was strong despite a relatively high herring biomass that year. Such exceptions to the rule are certainly to be expected, little or no overlap in time and/or space would for instance lead to reduced or no predation effects. Unfortunately, we do not have sufficient knowledge about the distribution of capelin larvae and young herring to judge whether such mechanisms were the reason for the anomaly observed in 1999.

Although a final and firm conclusion have not been reached, we think that the analyses reviewed in this paper clearly show that predation, and mainly predation by young herring, stands out as the most likely mechanism for sporadic recruitment failure. The high production of capelin larvae at the onset of the periods of rapid stock decline rules out recruitment overfishing (as for instance suggested by Hopkins and Nilssen, 1991) as a valid candidate mechanism. Likewise, the fact that rich capelin year classes have been produced in the same years as strong year classes of other fish species in this area renders the competition for food and death by starvation (as for instance suggested by Ushakov and Prozorkevich, 2002) a less likely candidate. Starvation among the capelin larvae, for instance because of shortage of suitable food, either during parts of or throughout the whole larval period cannot be ruled out, due to scarcity of relevant feeding studies of the larvae or monitoring of suitable food for the larvae. However, a comparative-feeding study showed that capelin larvae feed on smaller prey than do herring larvae and juveniles (Pedersen and Fossheim, 2008), suggesting little competition potential for these stages. For larger juvenile capelin, feeding studies indicate that there may be a larger potential for competition with herring (Huse and Toresen, 1996). The survival potential for capelin larvae in the absence of predators seems to be very high (Ivarjord et al., 2008).

Obviously, predation mortality and starvation mortality are not exclusive causal mechanisms, and predation mortality is likely modulated by larval growth (Anderson, 1988). Environmental variability, like general growth conditions, food availability, and amount of competition at the early life stages, will regulate predation mortality. For example, under similar juvenile herring concentration, fast-growing capelin will suffer less cumulative predation mortality relative to slow-growing capelin. Not only is the presence of the predator of importance, but also the growth environment of the larvae.

For capelin larvae, there is also another variable factor that might modulate the effect of predation, which is the variable time of spawning. The majority of capelin in the Barents Sea spawn from late February to early April but it has been known for many decades that some additional spawning takes place in summer and early autumn (Gjøsæter, 1998). Summer spawning will produce larvae that hatch near the end of the main feeding season, and which are much smaller than their counterparts from spring. Their distribution will normally be further to the east because late spawning normally takes place further east than the main spawning in spring. These factors might affect the vulnerability to predation of larvae from summer spawning compared with those from spring spawning. Summer spawning is considered to be negligible most years compared with the spring spawning, but if this still holds when considerable parts of the larvae from the spring-spawning season undergoes unusually high mortality rates during summer is unknown. An interesting topic for further studies is to determine how the quantity of summer spawning varies from year to year, and to investigate the fate of these larvae.

The area of the southern Barents Sea where capelin larvae are found in summer has a dynamic current system both temporarily and spatially, with yearly variations in main currents, and dynamic formations of mesoscale eddies on shorter time scales (Loeng, 1991; Pedersen et al., 2005; Hallfredsson, 2006). This will govern the distribution of drifting organisms such as capelin larvae, krill, and copepods (Sakshaug et al., 1994; Fossheim et al., 2005), as well as 0 -group cod. Juvenile herring undertakes feeding migrations in large schools in early spring and thereafter gradually disperse into smaller schools over a wider area during summer. The availability of abundant plankton prey advected with the Atlantic current and the Norwegian Coastal Current into the Barents Sea probably influence the feeding migrations of the herring. Further, eddies will most likely affect both vertical and horizontal small-scale overlap of capelin larvae with larvae predators and alternative prey for the predators (Fossheim et al., 2005).

A statistical multistage analysis investigating regulation factors from spawning $(S S B)$ to larvae, and between the stages larvae, 0 -group and 1 group for data from 1981 to 2006, showed that mortality between larvae and 0 -group and between 0 -group and 1-group was strongly density dependent (Hjermann et al., 2010). In addition to a negative effect of juvenile herring on recruitment, 0 -group cod and juvenile cod had negative effects, and winter temperature had a positive effect on recruitment. Hjermann et al. (2010) suggested that the strong density dependence could be due to a switching by cod from capelin larvae to other prey at low densities. The densitydependent mortality during the early life stages means that negative effects of fishing and predation on prespawning capelin and eggs would be reduced at age of recruitment.

\section{Management application}

Since capelin not only plays a pivotal role in the Barents Sea ecosystem but this stock is also subject to a fishery in periods, the ability to make prognoses for stock development in the short and medium term would allow for better management of capelin as well as of the stocks that relies heavily on capelin as prey. We consider further stock-recruit modelling along the lines outlined by Gjøsæter and Bogstad (1998) and Mikkelsen and Pedersen (2004) as the best approach. If a reliable stock-recruit function incorporating herring and other potential predators could be established, and these quantities could be predicted at least 1 year into the future, this relationship could easily be incorporated into the present capelin assessment model (Gjøsæter et al., 2002). The most logical way to do that is probably by extending the model from a target spawning biomass escapement to a target recruitment resulting 
from the spawning. It is possible to give a prognosis for the amount of herring in the Barents Sea from 1 to 3 years into the future. Although the recruitment indices for herring are noisy, they make it possible to identify very strong or very weak year classes at an early stage. However, it would be increasingly difficult to provide longer prognoses, and this would limit the scope of any model incorporating the effect of herring on other stocks in the ecosystem.

\section{Conclusions}

We have argued that there are good reasons to accept the "Hamre hypothesis", stating that young herring that enter the Barents Sea in various amounts is the underlying reasons for capelin recruitment failures and capelin stock collapses experienced in the recent period. However, the recent history of capelin recruitment suggests that the simplistic form of the hypothesis that abundant year classes of herring and recruitment success among capelin are exclusive events is not supported. As shown in Figure 7, some years deviate from the common pattern that abundant year classes of herring co-occur with recruitment failure among capelin. This should not be surprising, since the implicit assumption in the herring predation hypothesis, that there is full or at least a substantial overlap between the distribution of herring and capelin larvae, hardly holds in all years. Although information about the distribution of young herring and capelin larvae is lacking in many years and is incomplete in others, it is known that both distribution areas are changing from year to year, and it is highly likely that the amount of overlap between the two may vary from almost nonexistent to nearly complete. The overlap will also be influenced by the amount of late (summer) spawning capelin, such spawning usually takes place on the eastern spawning grounds (Gjøsæter, 1998; Carscadden et al., 2013). Additionally, other predators on capelin egg and larvae, and availability of alternative prey for the herring most likely should be taken into account. A reformulation of the original "Hamre hypothesis" saying that a high abundance of young herring is a likely cause, but not a sufficient requirement for a capelin stock collapse (Gjøsæter et al., 2009), may be a more relevant working hypothesis to go forward with in the continued search for a more complete knowledge of the complicated recruitment mechanisms in the Barents Sea capelin stock.

It is necessary to continue the monitoring of young herring and 0 -group capelin to get early warning of changes in the ecosystem. A close monitoring of young stages of herring and capelin can be used to predict the probability of a capelin stock collapse 2-4 years ahead and give corresponding predictions of food abundance available to cod and other predators. Continued effort should also be put into incorporating modelling of spatial overlap between young herring and capelin larvae, with aim to better understand the underlying mechanisms and to incorporate this understanding into future capelin stock-recruit models.

\section{Supplementary data}

Supplementary material is available at the ICESJMS online version of the manuscript.

\section{References}

Alvheim, O. 1985. Investigation on capelin larvae off Northern Norway and in the Barents Sea in 1981-1984. In The proceedings of the Soviet-Norwegian Symposium on The Barents Sea Capelin, Bergen, Norway 14-17 August 1984, pp. 171-183. Ed. by H. Gjøsæter. Institute of Marine Research, Bergen, Norway.
Anderson, J. T. 1988. A review of size dependent survival during prerecruit stages of fishes in relation to recruitment. Journal of Northwest Atlantic Fishery Science, 8: 55-66.

Anisimova, N., Berenboim, B., Gerasimova, O., Manushin, I., and Pinchukov, M. 2005. On the effect of red king crab on some components of the Barents Sea ecosystem. In Ecosystem Dynamics and Optimal Long-term Harvest in the Barents Sea Fisheries. Proceeding from the 11th Russian-Norwegian Symposium, pp. 298-306. Ed. by V. Shibanov. IMR/PINRO Joint Report Series, $2005 / 2$.

Bailey, K. M., and Houde, E. D. 1989. Predation on eggs and larvae of marine fishes and the recruitment problem. Advances in Marine Biology, 25: 1-83.

Bajkov, A. D. 1935. How to estimate the daily food consumption of fish under natural conditions. Transactions of the American Fishery Society, 65: 288-289.

Bogetveit, F. R., Slotte, A., and Johannessen, A. 2008. The ability of gadoids to take advantage of a short-term high availability of forage fish: The example of spawning aggregations in Barents Sea capelin. Journal of Fish Biology, 72: 1427-1449.

Carscadden, J. E., Gjøsæter, H., and Vilhjálmsson, H. 2013. Recruitment in the Barents Sea, Icelandic, and Eastern Newfoundland/Labrador Capelin (Mallotus villosus) Stocks. Progress in Oceanography, 114: $84-96$.

Carscadden, J. E., and Vilhjálmsson, H. 2002. Capelin-what are they good for? Introduction. ICES Journal of Marine Science, 59: 863-869.

Christensen, V. 1983. Predation by Sand Eel on Herring Larvae. ICES Council Meeting Documents 1983/L:27. 10 pp.

Christiansen, J. S., Præbel, K., Siikavuopio, S. I., and Carscadden, J. E. 2008. Facultative semelparity in capelin Mallotus villosus (Osmeridae) - an experimental test of a life history phenomenon in a sub-arctic fish. Journal of Experimental Marine Biology and Ecology, 360: 47-55.

Dalpadado, P., and Bogstad, B. 2004. Diet of juvenile cod (age 0-2) in the Barents Sea in relation to food availability and cod growth. Polar Biology, 27: 140-154.

DeBlois, E., and Leggett, W. C. 1993. Impact of amphipod predation on the benthic eggs of marine fish: An analysis of Calliopius laeviusculus bioenergetic demands and predation on the eggs of a beach spawning osmeriid (Mallotus villosus). Marine Ecology Progress Series, 69: 205-216.

Dolgov, A. V. 2002. The role of capelin (Mallotus villosus) in the foodweb of the Barents Sea. ICES Journal of Marine Science, 59: 1034-1045.

Dragesund, O., and Nakken, O. 1973. Relationship of parent stock size and year class strength in Norwegian spring spawning herring. In Fish Stocks and Recruitment, pp. 15-29. Ed. by B. Parrish. Rapports et procès-verbaux des réunions/Conseil permanent international pour l'exploration de la mer.

Durbin, E. G., Durbin, A. G., Langton, R. W., and Bowman, A. E. 1983. Stomach contents of silver hake, Merluccius bilinearis, and Atlantic Cod, Gadus morhua, and estimation of their daily rations. Fishery Bulletin, 81: 437-454.

Eriksen, E., Prozorkevich, D. V., and Dingsør, G. E. 2009. An evaluation of 0 -group abundance indices of Barents Sea Fish Stocks. The Open Fish Science Journal, 2: 6-14.

Falkenhaug, T., Tande, K. S., and Semenova, T. 1997. Diel, seasonal and ontogenetic variations in the vertical distributions of four marine copepods. Marine Ecology Progress Series, 149: 105-119.

Fossheim, M., Zhou, M., Tande, K. S., Pedersen, O. P., Zhu, Y. W., and Edvardsen, A. 2005. Interactions between biological and environmental structures along the coast of northern Norway. Marine Ecology Progress Series, 300: 147-158.

Gibson, R. N., and Ezzi, I. A. 1992. The relative profitability of particulate-feeding and filter-feeding in the herring, Clupea harengus L. Journal of Fish Biology, 40: 577-590.

Gjøsæter, H. 1995. Pelagic fish and the ecological impact of the modern fishing industry in the Barents Sea. Arctic, 48: 267-278. 
Gjøsæter, H. 1998. The population biology and exploitation of capelin (Mallotus villosus) in the Barents Sea. Sarsia, 83: 453-496.

Gjøsæter, H., and Bogstad, B. 1998. Effects of the presence of herring (Clupea harengus) on the stock-recruitment relationship of Barents Sea capelin (Mallotus villosus). Fisheries Research, 38: $57-71$.

Gjøsæter, H., Bogstad, B., and Tjelmeland, S. 2002. Assessment methodology for Barents Sea capelin, Mallotus villosus (Müller). ICES Journal of Marine Science, 59: 1086-1095.

Gjøsæter, H., Bogstad, B., and Tjelmeland, S. 2009. Ecosystem effects of the three capelin stock collapses in the Barents Sea. Marine Biology Research, 5: 40-53.

Gjøsæter, H., Bogstad, B., Tjelmeland, S., and Subbey, S. 2015. Retrospective evaluation of the Barents Sea capelin management advice. Marine Biology Research, 11: 135-143.

Gjøsæter, H., Dommasnes, A., and Røttingen, B. 1998a. Acoustic investigations of the size and distribution of the Barents Sea capelin stock 1972-1997. Fisken og Havet, 4: 1-71.

Gjøsæter, H., Dommasnes, A., and Røttingen, B. 1998b. The Barents Sea capelin stock 1972-1997. A synthesis of results from acoustic surveys. Sarsia, 83: 497-510.

Gjøsæter, J., Hansen, K., Sætre, R., and Westergaard, T. 1974. Investigations at the spawning grounds of capelin in 1974. Fiskets Gang, 60: 740-744.

Godiksen, J. A., Hallfredsson, E. H., and Pedersen, T. 2006. Effects of alternative prey on predation intensity from herring Clupea harengus and sandeel Ammodytes marinus on capelin Mallotus villosus larvae in the Barents Sea. Journal of Fish Biology, 69: 1807-1823.

Gundersen, A. C., and Gjøsæter, H. 1998. A comparison between abundance estimates of the Barents Sea capelin (Mallotus villosus Müller) at the larval, 0-group and 1-group stage, for the year classes 19811994. ICES Journal of Marine Science, 55: 95-101.

Hallfredsson, E. H. 2006. Fish predation on capelin larvae Mallotus villosus in the Barents Sea, in relation to recruitment. Doctor Scientiarum Thesis, Norwegian College of Fishery Science/ University of Tromsø, Tromsø. $210 \mathrm{pp}$.

Hallfredsson, E. H., and Pedersen, T. 2007. Effects of predation from pelagic 0-group cod (Gadus morhua) on mortality rates of capelin (Mallotus villosus) larvae in the Barents Sea. Canadian Journal of Fisheries and Aquatic Sciences, 64: 1710-1722.

Hallfredsson, E. H., and Pedersen, T. 2009. Effects of predation from juvenile herring (Clupea harengus) on mortality rates of capelin (Mallotus villosus) larvae. Canadian Journal of Fisheries and Aquatic Sciences, 66: 1693-1706.

Hallfredsson, E. H., Pedersen, T., and Præbel, K. 2007. Estimation of digestion rates for herring Clupea harengus $\mathrm{L}$. feeding on fish larvae. Journal of Fish Biology, 70: 638-643.

Hallfredsson, E. H., and Pope, J. G. 2007. Modelling the growth, mortality, and predation interactions of cod juveniles and capelin larvae in the Barents Sea using a novel proto-moment population dynamics model. ICES Journal of Marine Science, 64: 1313-1323.

Hamre, J. 1991. Interrelation between environmental changes and fluctuating fish populations in the Barents Sea. In Long-Term Variability of Pelagic Fish Populations and Their Environment. Proceedings of the International Symposium, Sendai, Japan, 14-18 November 1989, pp. 259-270. Ed. by T. Kawasaki, S. Tanaka, Y. Toba, and A. Taniguchi. Pergamon Press, Oxford.

Hamre, J. 1994. Biodiversity and exploitation of the main fish stocks in the Norwegian - Barents Sea ecosystem. Biodiversity and Conservation, 3: 473-492.

Helle, K. 1993. Distribution and abundance of early juvenile Arcto-Norwegian cod (Gadus morhua L.) in relation to water mass properties and prey abundance. Cand. Scient. Thesis. University of Bergen. $116 \mathrm{pp}$.

Hjermann, D. Ø., Bogstad, B., Dingsør, G. E., Gjøsæter, H., Ottersen, G., Eikeset, A. M., and Stenseth, N. C. 2010. Trophic interactions affecting a key ecosystem component: A multistage analysis of the recruitment of the Barents Sea capelin. Canadian Journal of Fisheries and Aquatic Sciences, 67: 1363-1375.

Hjort, J. 1914. Fluctuations in the great fisheries of Northern Europe, viewed in the light of biological research. Rapports et Procès-Verbaux des Réunions/Conseil Permanent International Pour l'exploration de la mer, 20: 1-228.

Hopkins, C. C. E., and Nilssen, E. M. 1991. The rise and fall of the Barents Sea capelin (Mallotus villosus): A multivariate scenario. Polar Research, 10: 535-546.

Huse, G. 1994. Interactions between herring (Clupea harengus L.) and capelin (Mallotus villosus Müller) in the Barents Sea. Cand. Scient. thesis. Department of Fisheries and Marine Biology University of Bergen, Bergen, Norway. 86 pp.

Huse, G., and Toresen, R. 1995. Predation by juvenile herring (Clupea harengus L.) on Barents Sea capelin (Mallotus villosus Müller) larvae. In Precision and Relevance of Pre-Recruit Studies for Fishery Management Related to Fish Stocks in the Barents Sea and Adjacent Waters. Proceedings of the Sixth IMR-PINRO Symposium Bergen, pp. 59-73. Ed. by A. Hylen. Institute of Marine Research, Bergen, Norway.

Huse, G., and Toresen, R. 1996. A comparative study of feeding habits of herring (Clupea harengus, Clupeidae, L.) and capelin (Mallotus villosus, Osmeridae, Müller) in the Barents Sea. Sarsia, 81: 143-153.

Huse, G., and Toresen, R. 2000. Juvenile herring prey on Barents Sea capelin larvae. Sarsia, 85: 385-391.

Hvingel, C., Kingsley, C. S. M., and Sundet, J. H. 2012. Survey estimates of king crab (Paralithodes camtschaticus) abundance off Northern Norway using GLMs within a mixed generalized gamma-binomial model and Bayesian inference. ICES Journal of Marine Science, 69: $1416-1426$

ICES. 2014a. Report of the Arctic Fisheries Working Group (AFWG) 23-29 April 2014, Lisbon, Portugal. ICES CM 2014/ACOM:05. $667 \mathrm{pp}$.

ICES. 2014b. Report of the Working Group on Widely Distributed stocks (WGWIDE) Copenhagen, Denmark, 26 August-1 September 2014. ICES CM 2014/ACOM:15. 938 pp.

ICES. 2015. Report of the Arctic Fisheries Working Group (AFWG), Hamburg, Germany, April 23-29 2015. ICES CM 2015/ ACOM:05. 623 pp.

Ivarjord, T., Pedersen, T., and Moksness, E. 2008. Effects of growth rates on the otolith increments deposition rate in capelin larvae (Mallotus villosus). Journal of Experimental Marine Biology and Ecology, 358: $170-177$.

Loeng, H. 1991. Features of the physical oceanographic conditions of the Barents Sea. Polar Research, 10: 5-18.

Magnusson, J. V. 1968. On the occurrence of capelin larvae in Icelandic waters in relation to temperature. Rapports et procès-verbaux des réunions/Conseil permanent international pour l'exploration de la mer, 158: 31 .

Michalsen, K., Dalpadado, P., Eriksen, E., Gjøsæter, H., Ingvaldsen, R., Johannesen, E., Jørgensen, L. L., et al. 2013. Marine living resources of the Barents Sea-Ecosystem understanding and monitoring in a climate change perspective. Marine Biology Research, 9: 932-947.

Mikkelsen, N. 2013. Predation on the demersal fish eggs of capelin Mallotus villosus and lumpsucker Cyclopterus lumpus in relation to recruitment. $\mathrm{PhD}$ thesis. Faculty of Biosciences, Fisheries and Economics, Department of Arctic and Marine Biology, University of Tromsø. 52 pp.

Mikkelsen, N., and Pedersen, T. 2004. How can the stock recruitment relationship of the Barents Sea capelin (Mallotus villosus) be improved by incorporating biotic and abiotic factors? Polar Research, 23: 19-26.

Munk, P. 2002. Larval sand lance (Ammodytes sp.) in the diet of small juvenile wolffish (Anarhichas spp.): Predatory interactions in frontal water masses off western Greenland. Canadian Journal of Fisheries and Aquatic Sciences, 59: 1759-1767. 
Øiestad, V., and Moksness, E. 1979. Interaction between Atlanto-Scandian herring larvae (Clupea harengus L.) and capelin larvae (Mallotus villosus) in concrete enclosure experiment. ICES C.M. 1979/F:52: 1-10.

Olson, R. J., and Boggs, H. 1986. Apex predation by yellowfin tuna (Thunnus albacares): Independent estimates from gastric evacuation and stomach contents, bioenergetics, and caesium concentrations. Canadian Journal of Fisheries and Aquatic Sciences, 43: 1760-1775.

Pedersen, O. P., Pedersen, T., Tande, K. S., and Slagstad, D. 2009a. Integrating spatial and temporal mortality from herring on capelin larvae: A study in the Barents Sea. ICES Journal of Marine Science, 66: $2183-2194$

Pedersen, O. P., Tande, K. S., Pedersen, T., and Slagstad, D. 2009 b. Advection and retention as life trait modulators of capelin larvae - a case study from the Norwegian coast and the Barents Sea. Fisheries Research, 97: 234-242.

Pedersen, O. P., Zhou, M., Tande, K. S., and Edvardsen, A. 2005. Eddy formation on the coast of North Norway - evidenced by synoptic sampling. ICES Journal of Marine Science, 62: 615-628.

Pedersen, T., and Fossheim, M. 2008. Diet of 0-group stages of capelin (Mallotus villosus), herring (Clupea harengus) and cod (Gadus morhua) during spring and summer in the Barents Sea. Marine Biology, 153: 1037-1046.

Pope, J. 2003. Golden ages or magic moments? Natural Resource Modeling, 16: 439-464.

Richardson, D. E., Hare, J. A., Fogarty, M. J., and Link, J. S. 2011. Role of egg predation by haddock in the decline of an Atlantic herring population. Proceedings of the National Academy of Sciences of the United States of America, 108: 13606-13611.

Sætre, R., and Gjøsæter, J. 1975. Ecological investigations on the spawning grounds of the Barents Sea capelin. Fiskeridirektoratets Skrifter, Serie Havundersøkelser, 16: 203-227.

Sakshaug, E., Bjørge, A., Gulliksen, B., Loeng, H., and Mehlum, F. 1994. Structure, biomass distribution, and energetics of the pelagic ecosystem in the Barents Sea: a synopsis. Polar Biology, 14: 405-411.

Scharf, F. S., Juanes, F., and Rountree, R. A. 2000. Predator size-prey size relationships of marine fish predators: Interspecific variation and effects of ontogeny and body size on trophic-niche breadth. Marine Ecology Progress Series, 208: 229-248.

Skaret, G., Akselsen, B. E., Nøttestad, L., Fernø, A., and Johannesen, A. 2002. Herring as cannibals. Brief Communication. Journal of Fish Biology, 61: 1050-1052.

Slotte, A., Mikkelsen, N., and Gjøsæter, H. 2006. Egg cannibalism in Barents Sea capelin in relation to a narrow spawning distribution. Journal of Fish Biology, 69: 187-202.

Smith, C., and Reay, P. 1991. Cannibalism in teleost fish. Reviews in Fish Biology and Fisheries, 1: 41-64.

Sundby, S., Bjørke, H., Soldal, A. V., and Olsen, S. 1989. Mortality rates during the early life stages and year-class strength of Northeast Arctic cod (Gadus morhua L.). Rapports et procès-verbaux des réunions/ Conseil permanent international pour l'exploration de la mer, 191: 351-358.

Tande, K. S., Drobysheva, S., Nesterova, V., Nilssen, E. M., Edvardsen, A., and Tereschenko, V. 2000. Patterns in the variations of copepod spring and summer abundance in the northeastern Norwegian Sea and the Barents Sea in cold and warm years during the 1980s and 1990s. ICES Journal of Marine Science, 57: $1581-1591$.

Templeman, W. 1948. The life history of the capelin (Mallotus villosus Müller) in Newfoundland waters. Research Bulletin Newfoundland Government Laboratory, 17: 1-151.

Toresen, R., Gjøsæter, H., and De Barros, P. 1998. The acoustic method as used in the abundance estimation of capelin (Mallotus villosus Müller) and herring (Clupea harengus Linne) in the Barents Sea. Fisheries Research, 34: 27-37.

Ushakov, N. G., and Prozorkevich, D. V. 2002. The Barents Sea capelin-a review of trophic interrelations and fisheries. ICES Journal of Marine Science, 59: 1046-1052.

Wiedmann, M. A., Pedersen, O. P., and Nilssen, E. M. 2012. The recruitment process of the Barents Sea capelin (Mallotus villosus) stock, 2001-2003. Fisheries Oceanography, 21: 379-392.

Windsland, K., Hvingel, C., Nilssen, E. M., and Sundet, J. H. 2014. Dispersal of the introduced red king crab (Paralithodes camtschaticus) in Norwegian waters: A tag-recapture study. ICES Journal of Marine Science, 71: 1966-1976. 